\title{
Benefits and Risks of Prolonged Cotrimoxazole Prophylaxis among People Living with HIV in Immune Reconstitution Phase: A Retrospective Cohort Study
}

\author{
Christian N. Francisco, ${ }^{1}$ Marissa M. Alejandria ${ }^{1,2}$ and Edsel Maurice T. Salvaña $a^{1,3}$ \\ ${ }^{1}$ Section of Infectious Diseases, Department of Medicine, College of Medicine and Philippine General Hospital, University of the Philippines Manila \\ ${ }^{2}$ Department of Clinical Epidemiology, College of Medicine, University of the Philippines Manila \\ ${ }^{3}$ Institute of Molecular Biology and Biotechnology, National Institutes of Health, University of the Philippines Manila
}

\begin{abstract}
Objectives. To determine the effect of prolonged cotrimoxazole prophylaxis (CP) in reducing hospitalization and opportunistic infection rates among people living with HIV (PLHIV) with CD4 count $>200$ cells $/ \mathrm{mm}^{3}$.

Methods. We retrospectively reviewed 349 medical charts of PLHIV with CD4 count (or T-cell count) of $>200$ cells $/ \mathrm{mm}^{3}$ enrolled in an HIV treatment hub in Manila, Philippines, from January 2004 to July 2016. Demographic, clinical characteristics and outcomes were extracted. Descriptive statistics were generated. Chi-square test for two proportions was done to compare the difference in outcomes between the $\mathrm{CP}$ and non-CP groups.

Results. Of the 349 patients, majority (96.6\%) were male with a mean age of 28 years (SD 6.4) and mean CD4 count of 373 cells $/ \mathrm{mm}^{3}$ (SD 148). CP was continued in 103 patients (29.5\%) with mean duration of 1.7 (SD 1.9) years. The prolonged CP group had more events of adverse drug reactions $(p<0.001)$, specifically minor cutaneous reactions $(p<0.001)$ and immunologic failures $(p<0.001)$, compared to the non-CP group. There were no statistically significant differences in the frequency of hospitalization, PJP (Pneumocystis jirovecii pneumonia), non-PJP, other respiratory illnesses, diarrhea, toxoplasmosis, tuberculosis, stage $3 / 4$ events and mortality, between the prolonged $\mathrm{CP}$ and non-CP groups.
\end{abstract}

Conclusion. We did not observe any additional benefit in giving prolonged CP among PLHIV with CD4 count $>200$ cells $/ \mathrm{mm}^{3}$. More adverse effects were also seen in the CP group.

Key Words: HIV, AIDS, cotrimoxazole prophylaxis, cohort

\section{INTRODUCTION}

Acquired Immune Deficiency Syndrome (AIDS) and opportunistic infections (OI) are the main cause of absenteeism, hospitalizations and mortality among people living with HIV (PLHIV). ${ }^{1}$ Prevention of OI is a standard of care among patients with CD4 $\leq 200$ cells/ $\mathrm{mm}^{3}$. Antiretroviral therapy (ART) indirectly prevents OI

Paper presented at the $48^{\text {th }}$ Philippine College of Physicians Annual Convention, May 2017, SMX Convention Center, Pasay City.

Corresponding author: Christian N. Francisco, MD Section of Infectious Diseases

Department of Medicine Philippine General Hospital

University of the Philippines Manila

Taft Avenue, Ermita, Manila 1000, Philippines

Email: christianfrancisco1@gmail.com by promoting immune reconstitution while prophylactic medications act directly on the pathogens. ${ }^{2}$

Cotrimoxazole is one of the recommended prophylaxis in AIDS patients. Cotrimoxazole prophylaxis $(\mathrm{CP})$ is initiated when CD4 count is $\leq 200$ cells $/ \mathrm{mm}^{3}$. In this subgroup of patients, there was reduction in the incidence of Pneumocystis jirovecii pneumonia (PJP) and mortality among those on $\mathrm{CP}^{3-6}$ Termination of $\mathrm{CP}$ is recommended after 
two consecutive CD4 count determination of $>200$ cells/ $\mathrm{mm}^{3}$ taken 3-6 months apart, ${ }^{7}$ wherein modest immune reconstitution was achieved. ${ }^{5,8}$

The World Health Organization (WHO) provides a flexible guideline on the use of cotrimoxazole prophylaxis. ${ }^{9}$ WHO recommends starting $\mathrm{CP}$ at CD4 count $\leq 350$ cells/ $\mathrm{mm}^{3}$ and stopping when CD4 count improves to $>350$ cells $/ \mathrm{mm}^{3}$. However, in areas with high burden of infectious diseases or in areas where CD4 count determination is not readily available, WHO recommends prolonged or lifelong prophylaxis even if the CD4 count is $>350$ cells $/ \mathrm{mm}^{3} .{ }^{9}$ This recommendation is supported by various African studies. Maintaining CP in this subgroup of patients reduces the incidence of death, hospitalization and malaria as shown in an African meta-analysis. ${ }^{10}$ In addition, a randomized controlled trial done in the Republic of Côte d'Ivoire (Ivory Coast) showed reduction in the incidence of stage 3/4 events, pneumonia and tuberculosis in the $\mathrm{CP}$ group, ${ }^{11}$ while diarrhea incidence was reduced among those maintained on $\mathrm{CP}$ as reported in a prospective cohort study in Uganda. ${ }^{12}$

In the Philippines, CP is initiated when CD4 count is $\leq 200$ cells $/ \mathrm{mm}^{3}$ but with variable timing of discontinuation despite having a high burden of infectious diseases. There is no local data on the role of prolonged $\mathrm{CP}$ in improving clinical outcomes among Filipino PLHIV with CD4 count $>200$ cells $/ \mathrm{mm}^{3}$. We conducted a retrospective cohort study to compare the incidence of hospitalization and other infections between patients maintained on prolonged $\mathrm{CP}$ and not on CP.

\section{METHODS}

\section{Study Design and Setting}

This was a retrospective cohort study conducted at the HIV treatment hub of the Philippine General Hospital (PGH). The study was approved by the University of the Philippines Manila-Research Ethics Board (UPM-REB). All patient records were handled with strict confidentiality in accordance to the Philippine AIDS Law (Republic Act 8504). Subjects were identified using a study identifier (SID) number. All research data obtained were kept in a password-protected electronic database.

\section{Study Population and Patient Selection}

Assuming a hospitalization rate of $13 \%$ in the prolonged $\mathrm{CP}$ group and $19 \%$ in the non-CP group ${ }^{13}$, the computed sample size was 1,170 patients (585 per group) with CD4 count $\geq 200$ cells $/ \mathrm{mm}^{3}$ to detect a $6 \%$ difference in hospitalization with $80 \%$ power at 0.05 level of significance.

We retrospectively reviewed 876 medical records of patients enrolled from January 2004 to August 2016. We included 349 patients with CD4 count $\geq 200 \mathrm{cells} / \mathrm{mm}^{3}$. Five hundred twenty-seven (527) patient records were excluded due to the following reasons: 507 had CD4 count $<200$ cells $/ \mathrm{mm}^{3}, 8$ had prior treatment with cotrimoxazole (non- prophylactic use), while 12 presented with the outcomes of interest prior to CD4 count improvement to $\geq 200$ cells $/ \mathrm{mm}^{3}$.

We reviewed the clinic database from the date of enrollment until the last follow up visit. The following were recorded: age, sex, baseline and subsequent CD4 counts, presence and duration of cotrimoxazole prophylaxis, presence and duration of ART and other medications. The patients were categorized into the prolonged $\mathrm{CP}$ group and non-CP group. Prolonged CP was defined as continued administration of cotrimoxazole at CD4 count $\geq 200$ cells $/ \mathrm{mm}^{3}$. Non-CP group consisted of patients whose cotrimoxazole prophylaxis were discontinued upon achieving a CD 4 count of $\geq 200$ cells $/ \mathrm{mm}^{3}$. Study outcomes were extracted from the time of CD4 count improvement $\left(\geq 200\right.$ cells $\left./ \mathrm{mm}^{3}\right)$ until the last recorded clinic follow up for both groups. The primary outcome was hospitalization from all causes.

Secondary outcomes included immunologic failure (defined as decrease in CD4 from $\geq 200$ cells $/ \mathrm{mm}^{3}$ to $<200$ cells $/ \mathrm{mm}^{3}$ ), PJP pneumonia, non-PJP (defined as pneumonia caused by other bacterial pathogens) and respiratory illness (defined as any episode of viral/bacterial upper respiratory tract infections).

Data on adverse drug reaction (ADR), defined as any untoward drug related events such as minor cutaneous manifestations (rash), Stevens-Johnson syndrome (SJS) and severe anemia (hemoglobin $<70 \mathrm{~g} / \mathrm{L}$ ), were also collected.

\section{Statistical Analysis}

Frequency distribution, measures of central tendency and measures of variability were generated. Chi-square test was performed using STATA Version 14 (Stata Corp, College Station, Texas, USA) to determine whether there was a significant difference in the frequencies between the two groups (prolonged CP versus non-CP groups).

\section{RESULTS}

A total of 349 patient records were included in the study analysis, 103 in the prolonged CP group and 246 in the non-CP group. Majority were males (96.6\%) with a mean age of 28.3 years (SD 6.4). The mean estimated duration of HIV infection was 3.8 years (SD 2.1) and the mean duration of ART use was 2.7 years (SD 2.0).

Upon study entry, 145 were asymptomatic (41.5\%). Among the 349 study participants included, 103 (29.5\%) were on $\mathrm{CP}$ with a mean duration of 1.7 years (SD 1.8).

In the $\mathrm{CP}$ group, majority of the participants were in the $200-350$ cells $/ \mathrm{mm}^{3}$ CD4 category (69.9\%) while the remaining proportion (30.1\%) had CD4 $>350$ cells $/ \mathrm{mm}^{3}$.

Baseline demographic, laboratory and clinical characteristics of the study participants are summarized in Table 1.

The CP group had significantly more cases of immunologic failures $(24.3 \%$ vs $0.8 \%, \mathrm{p}<0.001)$ and ADRs (31.1\% vs $10.2 \%, \mathrm{p}<0.001)$ compared to the non-CP group. 
The most common ADR was minor cutaneous reactions (rash) which accounted for $86 \%$. Sub-analysis of each specific ADR showed more cases of minor cutaneous reactions (rash) $(26.2 \%$ vs $8.9 \%, \mathrm{p}<0.001)$ while significant difference in the occurrence of SJS and severe anemia were not seen between the two groups (Table 2). In the CP group, $37.5 \%$ of all ADR were due to cotrimoxazole (9 minor cutaneous reactions, 1 severe anemia, 2 SJS). Other medications commonly implicated in the development of ADR in this group included ART (nevirapine, zidovudine) in $25.0 \%$ and anti-tuberculosis medications in $15.6 \%$.

ART was the implicated drug in $44.0 \%$ of all ADRs in the non-CP group (minor cutaneous reactions (7), severe anemia (2), SJS(2). In this group, other drugs (Table 3)

Table 1. Baseline Characteristics of 349 PLHIV in Immune Reconstitution Phase with or without Prolonged Cotrimoxazole Prophylaxis

\begin{tabular}{|c|c|c|}
\hline & $\mathrm{CP}(\mathrm{N}=103)$ & Non-CP (N=246) \\
\hline Mean age; SD (years) & $28.4 ; 6.4$ & $28.3 ; 6.3$ \\
\hline Male Sex (\%) & $99(96.1 \%)$ & $238(96.7 \%)$ \\
\hline $\begin{array}{l}\text { Mean CD4 count ; SD (cells } / \mathrm{mm}^{3} \text { ) } \\
200-349 \text { cells } / \mathrm{mm}^{3}(\%) \\
\geq 350 \text { cells } / \mathrm{mm}^{3}(\%)\end{array}$ & $\begin{array}{l}373 ; 148 \\
72(69.9 \%) \\
31(30.1 \%)\end{array}$ & $\begin{array}{c}372 ; 147 \\
111(45.1 \%) \\
135(54.9 \%)\end{array}$ \\
\hline Mean duration of CP at CD4 > 200; SD (years) & $1.7 ; 1.9$ & N/A \\
\hline ART use (\%) & $103(100 \%)$ & $216(87.8 \%)$ \\
\hline $\begin{array}{l}\text { Mean duration of ART use (years) } \\
\text { Range of duration of ART use }\end{array}$ & $\begin{array}{c}2.7 ; 2.0 \\
230 \text { days to } 8 \text { years }\end{array}$ & $\begin{array}{c}2.7 ; 2.0 \\
30 \text { days to } 7 \text { years }\end{array}$ \\
\hline $\begin{array}{l}\text { Symptomatology at CD4 > } 200 \text { (\%) } \\
\text { Asymptomatic } \\
\text { Fever } \\
\text { Respiratory symptoms } \\
\text { Weight loss } \\
\text { Lymphadenopathy } \\
\text { Urethral/ Vaginal Discharge } \\
\text { Skin Lesions } \\
\text { Others }\end{array}$ & $\begin{aligned} 46 & (44.7 \%) \\
7 & (6.8 \%) \\
16 & (15.5 \%) \\
8 & (7.8 \%) \\
20 & (19.4 \%) \\
2 & (1.8 \%) \\
26 & (25.2 \%) \\
25 & (24.3 \%)\end{aligned}$ & $\begin{array}{c}99(40.2 \%) \\
17(6.9 \%) \\
29(11.8 \%) \\
30(12.2 \%) \\
47(19.1 \%) \\
2(0.8 \%) \\
62(25.2 \%) \\
50(20.3 \%)\end{array}$ \\
\hline $\begin{array}{l}\text { Other OI prophylaxis (\%) } \\
\text { Azithromycin } \\
\text { INH }\end{array}$ & $\begin{array}{l}25(24.3 \%) \\
24(23.3 \%)\end{array}$ & $\begin{array}{l}12(4.9 \%) \\
84(34.1 \%)\end{array}$ \\
\hline
\end{tabular}

Table 2. Outcomes among 349 PLHIV in Immune Reconstitution Phase with or without Prolonged Cotrimoxazole Prophylaxis

\begin{tabular}{lccc}
\hline & $\mathbf{C P}(\mathbf{N}=103)$ & non-CP (N=246) & p-value \\
Primary Outcome (\%) & & & \\
Hospitalization & $11(10.7 \%)$ & $17(6.9 \%)$ & 0.28 \\
\hline Secondary Outcomes(\%) & & & \\
PCP & $1(0.9 \%)$ & $0(0 \%)$ & 0.12 \\
Non-PCP & $1(0.9 \%)$ & $1(0.4 \%)$ & 0.52 \\
Respiratory Illness other than Pneumonia & $28(27.2 \%)$ & $63(25.6 \%)$ & 0.76 \\
Active Tuberculosis(TB) & $16(15.5 \%)$ & $27(10.9 \%)$ & 0.24 \\
Pulmonary TB & $12(11.6 \%)$ & $17(6.9 \%)$ & 0.14 \\
$\quad$ Extrapulmonary TB & $3(2.9 \%)$ & $9(3.6 \%)$ & 0.73 \\
Disseminated TB & $1(0.9 \%)$ & $1(0.4 \%)$ & 0.52 \\
Latent Tuberculosis & $2(1.8 \%)$ & $1(0.4 \%)$ & 0.16 \\
Diarrhea & $10(9.7 \%)$ & $11(4.5 \%)$ & 0.06 \\
Toxoplasmosis & $1(0.9 \%)$ & $0(0 \%)$ & 0.12 \\
Any stage 3 or 4 events & $5(4.9 \%)$ & $6(2.4 \%)$ & 0.24 \\
Immunologic Failure & $25(24.3 \%)$ & $2(0.8 \%)$ & $<0.001$ \\
Development of resistance to current ART regimen & $2(1.9 \%)$ & $6(2.4 \%)$ & 0.78 \\
Mortality & $3(2.9 \%)$ & $5(2 \%)$ & 0.61 \\
Adverse Drug Reactions & $32(31.1 \%)$ & $25(10.2 \%)$ & $<0.001$ \\
$\quad$ Minor cutaneous (rash) & $27(26.2 \%)$ & $22(8.9 \%)$ & $<0.001$ \\
SJS & $2(1.9 \%)$ & $2(0.8 \%)$ & 0.37 \\
Severe Anemia & $3(2.9 \%)$ & $2(0.8 \%)$ & 0.13 \\
\hline
\end{tabular}


Table 3. Common Implicated Medications for Adverse Drug Reactions among PLHIV in Immune Reconstitution Phase with or without Prolonged Cotrimoxazole Prophylaxis

\section{$\mathrm{CP}(\mathrm{N}=32)$}

Cotrimoxazole - Anemia (1)

SJS (2)

Minor cutaneous (9)

Isoniazid (INH) - Minor cutaneous (1)

Tuberculosis Medications - Minor cutaneous (4)

ART: Nevirapine (NVP) - Minor cutaneous (6)

Zidovudine (AZT) - Anemia (2)

Non-steroidal anti-inflammatory drugs (NSAIDS) - Minor cutaneous (4)

Others (includes supplements, topical agents) - Minor cutaneous (3)
Non- $\mathrm{CP}(\mathrm{N}=25)$

ART: NVP - SJS (2),

Minor cutaneous (7)

AZT - Anemia (2)

INH - Minor cutaneous (2)

TB Medications - Minor cutaneous (4)

NSAIDS - Minor cutaneous (2)

Others (includes supplements, topical agents) - Minor cutaneous (6)

Table 4. Reasons for Hospitalizations and Mortality among PLHIV in Immune Reconstitution Phase with or without Prolonged Cotrimoxazole Prophylaxis

\begin{tabular}{ll}
$\mathbf{C P}(\mathbf{N}=\mathbf{1 1})$ & Non- $\mathbf{C P}(\mathbf{N}=\mathbf{1 7})$ \\
\hline Severe anemia (3) & Severe anemia (2) \\
SJS (2) & SJS (2) \\
PCP (1) & PTB (1) \\
PTB (1) & Diarrhea (1) \\
unspecified (1) & Herpes zoster (1) \\
Mortality (3) - 2 PTB and immunologic failure & Severe cutaneous rash (1) \\
& Respiratory illness (3) \\
& FUO (1) \\
& Mortality (5) - 1 Gl obstruction \\
& 1 immunologic failure \\
& 3 ART-naïve \\
\hline
\end{tabular}

that commonly caused ADRs included anti-tuberculosis medications (24.0\%) and NSAIDS (8\%). Patients who developed SJS and severe anemia were hospitalized and discharged improved.

There were also no significant differences in hospitalization, PJP, non-PJP, respiratory illness, active TB, latent $\mathrm{TB}$, diarrhea, toxoplasmosis, other stage 3/4 events specifically oral candidiasis and herpes simplex, development of resistance to current ART regimen and mortality (Table 2).

The reasons for the hospitalizations in each group are summarized in Table 4. Among the patients who died, three were in the CP group [with active pulmonary TB and developed immunologic failure (2), unknown cause (1)] and five (5) were in the non- $\mathrm{CP}$ group [gastrointestinal obstruction (1), 1 immunologic failure (1), 3 ART-naive (3)].

\section{DISCUSSION}

CP decreases the incidence of opportunistic infections among PLHIV with CD4 count $<200$ cells $/ \mathrm{mm}^{3}$, however good evidence is lacking on its benefit among those with CD4 count $>200$ cells $/ \mathrm{mm}^{3}$ or those who are in the immune reconstitution phase. ${ }^{9,13,14}$

In this study, patients on $\mathrm{CP}$ once had a CD 4 count $<200$ cells $/ \mathrm{mm}^{3}$, which prompted its initiation and maintained thereafter until the CP termination criteria was fulfilled. The average increase in CD4 count was 150 cells $/ \mathrm{mm}^{3}$ for 6 months while on standard WHO recommended ART. ${ }^{15}$ An average of two years of ART exposure was needed to achieve moderate immune reconstitution (CD4 >200 cells/ $\left.\mathrm{mm}^{3}\right)$ which was consistent to the mean duration (1.7 years) of $\mathrm{CP}$ in our cohort study. ${ }^{16}$ There was a proportion of patients on prolonged $\mathrm{CP}$ who had a CD4 count $>350$ cells $/ \mathrm{mm}^{3}$ at the time of the study. This subgroup of patients were maintained on $\mathrm{CP}$ because they did not fulfill the $\mathrm{CP}$ termination criteria (2 consecutive $\mathrm{CD} 4$ count determination above 200 cells $/ \mathrm{mm}^{3}$ and CD 4 count monitoring were not consistently done during the 3-6 months interval).

This study did not show the benefits of CP in reducing hospitalizations and other coinfections as reported in previous studies. However, our study showed that $\mathrm{CP}$ was not safe among PLHIV with CD4 count $>200$ cells $/ \mathrm{mm}^{3}$ due to the high incidence of ADR.

Cotrimoxazole is a known culprit for ADR with rash as the most common presentation. ${ }^{17}$ Aside from the high immunogenicity of its sulfa-component, patients with lower CD4 count or those with initially low CD4 count have a higher risk for cutaneous ADR. ${ }^{18}$

In this study, $68.4 \%$ patients who experienced ADR had a CD4 count $<350$ cells $/ \mathrm{mm}^{3}$. Anemia was more common among those on $\mathrm{CP}$ as previously shown in a randomized controlled trial in children and adolescents in Africa. ${ }^{13}$ These findings are in agreement with the result of this study. However, it should be noted that zidovudine induced anemia was the main reason for the occurrence of this outcome in both groups. The effect of poly-pharmacy in ADR needs to be investigated.

The incidence of immunologic failure was higher in the $\mathrm{CP}$ group. This might not be due to the effect of cotrimoxazole but rather on the difference in the level of 
immunosuppression between the two groups. There was a higher proportion of patients in the $200-350$ cells $/ \mathrm{mm}^{3}$ category in the $\mathrm{CP}(69.9 \%)$ as compared to the non-CP group (45.1\%). The erratic rise and fall of CD4 count was commonly observed among patients who once had a very low CD4 count at the time of HIV diagnosis. ${ }^{19}$ Due to the retrospective nature of this study, factors contributing to immunologic failure in this subgroup of patients (CD4 200-350 cells $/ \mathrm{mm}^{3}$ ) were not accounted for. These included physical stress, age, smoking habits, malnutrition, compliance to ART, HIV mutations and resistance. ${ }^{20}$

In this study, CP was not beneficial among PLHIV with CD4 count $>200$ cells $/ \mathrm{mm}^{3}$. There was no difference in the incidence of hospitalizations between the two groups. This is in contrast to the result of a randomized controlled trial in Africa that showed a decrease in the incidence of hospitalizations among patients who continued $\mathrm{CP} .{ }^{13}$ It is important to note that the reduction in hospitalization rates in that study were mostly due to malaria and other infections (sepsis and meningitis). ${ }^{13}$ None in our cohort study was diagnosed with those coinfections.

Pneumonia (PJP and non-PJP) are common causes of morbidity among PLHIV and is usually seen among those who are severely immunocompromised. However, minimal risks still exist among PLHIV with CD4 $>200$ cells $/ \mathrm{mm}^{3} .^{21}$ The reduction in PJP and non-PJP rates were not shown in this study. The results agree with the findings of a cohort study involving 4050 PLHIV in Asia showing no difference in PJP rates between $\mathrm{CP}$ and non- $\mathrm{CP}$ groups. This observation also applies to those with CD4 count of 200 to $>300$ cells $/ \mathrm{mm}^{3} .^{5}$

Published studies reporting on the reduction of nonPJP rates are conflicting. ${ }^{11,22}$ The conflicting results might be due to the differences in the prevailing bacterial pathogens, resistance patterns and vaccination coverage among study participants. The low rates of non-PJP in our cohort study might be explained by the active vaccination practices in our treatment hub.

Our study is in agreement with the findings from other cohort studies showing no reduction in the rates of respiratory illnesses, diarrhea, toxoplasmosis and other stage 3 and 4 events. ${ }^{11}$ These AIDS-defining conditions are commonly seen among the severely immunocompromised which could have explained the low number of outcomes in this study. Moreover, mild symptoms from non-specific respiratory illnesses (upper respiratory tract infections) and non-specific enteritis presenting as diarrhea might have been disregarded by the patient and physician, hence under reporting of cases.

Tuberculosis (TB) is common among PLHIV and the risk of infection is present regardless of the CD4 count level. Cotrimoxazole has an in vitro activity against Mycobacterium tuberculosis ${ }^{23}$ but its clinical utility in preventing infection needs to be investigated. Based on the TREAT Asia HIV Observational Database (TAHOD), TB incidence was reduced among patients on $\mathrm{CP}$ but this effect was seen only among PLHIV with CD4 count $<200$ cells $/ \mathrm{mm}^{3}$. No significant reduction was found for those on $\mathrm{CP}$ among PLHIV with CD4 count $>200$ cells $/ \mathrm{mm}^{3}{ }^{24}$ In a separate African cohort study, a reduction in tuberculosis rate was not shown for all subgroups of CD4 count among those on CP. ${ }^{11}$ These findings are consistent with our results showing minimal TB reduction even in areas with high TB prevalence.

Reduction in mortality and AIDS-related morbidity is the main goal of early ART initiation. Prophylactic medications prevent AIDS defining coinfections that increase the risk for death. Small number of mortalities were reported in our cohort study but the trend showed that mortality rate between groups were not statistically different.

Our result agreed with previous studies that $\mathrm{CP}$ has no benefit in reducing over-all cause of mortality. ${ }^{11,22}$ However, reduction in mortality from malaria has been shown in areas where malaria is highly endemic. ${ }^{22}$ This is due to the anti-Plasmodium activity of cotrimoxazole..$^{22,25}$

There were some limitations in this study. The retrospective nature of the study prevented us to account for outcomes that were not recorded in the medical charts, including mild symptoms that may not necessitate medical consult. Even though we included all eligible patients in the analysis, the desired sample size was not met. This limitation could explain the lack of significant differences for other major outcomes. Moreover, the small number of patients in immune reconstitution and small number of outcomes recorded prohibited further statistical tests to determine associated factors. A well designed double blinded randomized controlled trial, enrolling patients with no history of CD4 count $<200$ cells $/ \mathrm{mm}^{3}$, is necessary to provide more data on the benefits of CP.

\section{CONCLUSION}

This study did not show the beneficial effect of $\mathrm{CP}$ in reducing hospitalization and reduction in opportunistic infection rates among PLHIV with CD4 count $>200$ cells/ $\mathrm{mm}^{3}$. Moreover, patients on prolonged $\mathrm{CP}$ were at higher risk for developing ADR.

\section{Statement of Authorship}

All authors participated in data collection and analysis, and approved the final version submitted.

\section{Author Disclosure}

All authors declared no conflicts of interest.

\section{Funding Source}

This paper was funded by the authors.

\section{REFERENCES}

1. The Australian Government's Overseas Aid Program, HIV/AIDS and Development in Asia and the Pacific: a Lengthening Shadow. The Potential Economic Impact of AIDS in Asia and the Pacific [Internet]. 
2001 [cited 2017 Mar]. Available from: http://www.hivpolicy.org/ Library/HPP000054.pdf.

2. Jacobson M. Clinical Implications of Immune Reconstitution in AIDS. HIV InSite [Internet]. 2006 [cited $2017 \mathrm{Mar}$ ]. Available from: http:// hivinsite.ucsf.edu/InSite?page=kb-03-04-03.

3. Suthar AB, Granich R, Mermin J, Van Rie A. Effect of cotrimoxazole on mortality in HIV-infected adults on antiretroviral therapy: a systematic review and meta-analysis. Bull World Health Organ. 2012; 90(2):128C-138C. doi:10.2471/BLT.11.093260. Epub 2011.Oct 24.

4. Walker AS, Ford D, Gilks CF, Munderi P, Ssali F, Reid A, et al. Daily co-trimoxazole prophylaxis in severely immunosuppressed HIV-Infected adults in Africa started on combination antiretroviral therapy : an observational analysis of the DART cohort. Lancet. 2010; 375(9722):1278-86. doi: 10.1016/S0140-6736(10)60057-8. Epub 2010 Mar 27.

5. Lim PL, Zhou J, Ditangco RA, Law MG, Sirisanthana T, Kumarasamy $\mathrm{N}$, et al. Failure to prescribe pneumocystis prophylaxis is associated with increased mortality, even in the cART era: results from the Treat Asia HIV observational database. J Int AIDS Soc. 2012; 15(1):1.

6. Lopez Bernaldo De Quiros JC, Miro JM, Pena JM, Podzamczer $\mathrm{D}$, Alberdi JC, Martínez E, et al. A randomized trial of the discontinuation of primary and secondary prophylaxis against Pneumocystis carinii pneumonia after highly active antiretroviral therapy in patients with HIV infection. N Engl J Med. 2001; 344(3):159-67.

7. Centers for Disease Control and Prevention and National Institutes of Health, AIDSinfo: Guidelines for Prevention and Treatment of Opportunistic Infections in HIV-infected Adults and Adolescents [Internet]. 2013 [cited 2017 Mar]. Available from: https://aidsinfo. nih.gov/contentfiles/lvguidelines/adult_oi.pdf.

8. Hirsch HH, Kauffman G, Sendi P, Battegay M.Immune Reconstitution in HIV-Infected Patients. Clin Infect Dis. 2004; 38(8);1159-66.

9. World Health Organization. Guidelines on Co-trimoxazole Prophylaxis for HIV-Related Infections Among Children, Adolescents and Adults Recommendations for a public health approach [Internet]. 2006 [cited 2017 Mar]. Available from: https://www.who.int/hiv/pub/ guidelines/ctx/en/.

10. Suthar AB, Vitoria MA, Nagata JM, Anglaret X, Mbori-Ngacha $\mathrm{D}$, Sued $\mathrm{O}$, et al. Co-trimoxazole prophylaxis in adults, including pregnant women, with HIV: a systematic review and meta-analysis. Lancet HIV. 2015; 2(4):137-50.

11. Anglaret X, Chêne G, Attia A, Toure S, Lafont S, Combe P, et al. Early chemoprophylaxis with trimethoprim- sulphamethoxazole for HIV-1-infected adults in Abidjan, Côte d'Ivoire: a randomised trial. Lancet. 1999; 353(9163):1463-8.

12. Mermin J, Lule J, Ekwaru JP, Malamba S, Downing R, Ransom $\mathrm{R}$, et al. Effect of co-trimoxazole prophylaxis on morbidity, mortality, CD4-cell count, and viral load in HIV infection in rural Uganda. Lancet. 2004; 364(9443):1428-34.

13. Bwakura-Dangarembizi M, Kendall L, Bakeera-Kitaka S, NahiryaNtege P, Keishanyu R, Nathoo K, et al. A randomized trial of prolonged co-trimoxazole in HIV-Infected children in Africa. N Engl J Med. 2014; 370(1):41-53.
14. Campbell JD, Moore D, Degerman R, Kaharuza F, Were W, Muramuzi E, et al. HIV-Infected Ugandan adults taking antiretroviral therapy with CD4 counts $>200$ cells/uL who discontinue cotrimoxazole prophylaxis have increased risk of malaria and diarrhea. Clin Infect Dis. 2012; 54(8):1204-11.

15. Mrudula ND, Suwarna UP, Khadse R, Minal P, Shubhangi DK. Statistical analysis and evaluation of CD4 Count after 6 months on ART. Indian J Community Med. 2012; 37(4):266-7.

16. Lok JJ, Bosch RJ, Benson CA, Collier AC, Robbins GK, Shafer $\mathrm{RW}$, et al. Long-term increase in CD4+ $\mathrm{T}$ cell counts during combination antiretroviral therapy for HIV-1 infection. AIDS. 2010; 24(12):1867-76.

17. Sisay M, Bute D, Edessa D, Mengistu G, Amare F, Gashaw T, et al. Appropriateness of Cotrimoxazole prophylactic therapy among HIV/ AIDS patients in public hospitals in Eastern Ethiopia: a retrospective evaluation of clinical practice. Front Pharmacol. 2018; 9:727.

18. Gonzalez-Martin G, Yanez CG, Gonzalez-Contreras L, Labarca J. Adverse drug reactions (ADRs) in patients with HIV infection. A prospective study. Int J Clin Pharmacol Ther. 1999; 37(1):34-40.

19. Gezie LD. Predictors of CD4 count over time among HIV patients initiated ART in Felege Hiwot Referral Hospital, northwest Ethiopia: multilevel analysis. BMC Res Notes. 2016; 9:377.

20. Montarroyos UR, Miranda-Filho DB, Cesar CC, Souza WV, Lacerda $\mathrm{HR}$, Albuquerque Mde F, et al. Factors related to changes in CD4+ T-cell counts over time in patients living with HIV/AIDS: a multilevel analysis. PLoS One. 2014;9(2):e84276.

21. Koletar SL, Heald AE, Finkelstein D, Hafner R, Currier JS, McCutchan JA, et al. A prospective study of discontinuing primary and secondary Pneumocystis carinii pneumonia prophylaxis after CD4 cell count increase to >200x106/L. AIDS. 2001; 15(12):1509-15.

22. Polyak CS, Yuhas K, Singa B, Khaemba M, Walson J, Richardson BA, et al. Cotrimoxazole prophylaxis discontinuation among antiretroviral treated HIV-1-infected adults in Kenya: a randomized non-inferiority trial. PLoS Med. 2016; 13(1):e1001934. doi: 10.1371/journal. pmed.1001934. eCollection 2016 Jan.

23. Davis NL, Barnett EJ, Miller WC, Dow A, Chasela CS, Hudgens MG, et al. Impact of daily Cotrimoxazole on clinical malaria and asymptomatic parasitemias in HIV-exposed, uninfected infants. Clin Infect Dis. 2015; 61(3):368-74. doi: 10.1093/cid/civ309. Epub 2015 Apr 21. PMID: 25900173; PMCID: PMC4542924.

24. Ku SW, Jiamsakul A, Joshi K, Pasayan MKU, Widhani A, Chaiwarith $\mathrm{R}$, et al. Cotrimoxazole pophylaxis decreases tuberculosis risk among Asian patients with HIV.J Int AIDS Soc. 2019; 22(3):e25264.

25. Manyando C, Njunju EM, D'Alessandro U, Van Geertruyden JP. Safety and efficacy of Co-trimoxazole for treatment and prevention of Plasmodium falciparum malaria: a systematic review. PLoS One. 2013;8(2):e56916. 